\title{
HICHEM GHORBEL, Le Monde chez Diderot. Connaissance, interprétation et signification
}

\section{Eszter Kovács}

\section{(2) OpenEdition}

\section{Journals}

\section{Edizione digitale}

URL: https://journals.openedition.org/studifrancesi/22696

DOI: 10.4000/studifrancesi.22696

ISSN: 2427-5856

\section{Editore}

Rosenberg \& Sellier

\section{Edizione cartacea}

Data di pubblicazione: 1 avril 2020

Paginazione: 176

ISSN: 0039-2944

\section{Notizia bibliografica digitale}

Eszter Kovács, «HICHem GHoRbeL, Le Monde chez Diderot. Connaissance, interprétation et signification», Studi Francesi [Online], 190 (LXIV | I) | 2020, online dal 01 mai 2020, consultato il 03 août 2021. URL: http:// journals.openedition.org/studifrancesi/22696 ; DOI: https://doi.org/10.4000/studifrancesi.22696

Questo documento è stato generato automaticamente il 3 août 2021.

\section{cc) (i) $\odot$}

Studi Francesi è distribuita con Licenza Creative Commons Attribuzione - Non commerciale - Non opere derivate 4.0 Internazionale. 


\title{
HICHEM GHORBEL, Le Monde chez Diderot. Connaissance, interprétation et signification
}

\author{
Eszter Kovács
}

\section{NOTIZIA}

HICHEM GHORBEL, Le Monde chez Diderot. Connaissance, interprétation et signification, Paris, L'Harmattan, 2018, «Ouverture philosophique», 198 pp.

1 Comme le précise Hichem Ghorbel dans l'introduction du livre, son objectif est d'accorder ou de rendre à Diderot le statut de philosophe, celui d'un penseur authentique. Il choisit pour ce but d'observer le matérialisme de Diderot et se concentre sur un corpus composé de trois œuvres: la Lettre sur les aveugles, les Pensées sur l'interprétation de la nature et Le Rêve de D'Alembert. Il fait un bref parcours de la problématique de la philosophie diderotienne dans l'introduction en cherchant à répondre aux questions suivantes: Pourquoi a-t-on refusé le statut de philosophe à Diderot? Quels étaient les principaux arguments des spécialistes qui ont néanmoins réclamé ce statut? Ghorbel souhaite confirmer de sa part l'originalité de la pensée de Diderot en mettant les trois ouvrages mentionnés ci-dessus à l'épreuve.

2 La première partie du livre est consacrée à la Lettre sur les aveugles. On y trouve une analyse valorisante de l'ouvrage tant sur le plan philosophique que sur le plan éthique. L'auteur cherche à voir en quoi l'approche de Diderot du problème Molyneux est novatrice par rapport aux réflexions précédentes. Dans la deuxième partie, Ghorbel considère les Pensées sur l'interprétation de la nature comme un anti-discours de la méthode, dirigé contre le modèle géométrique de Spinoza, le modèle mécanique de Descartes et contre tous ceux qu'il appelle les «méthodistes». En apparence discontinues et ne suivant aucune méthode fixe, ces Pensées avancent l'interprétation de la nature comme le grand tout en mouvement dans la philosophie de Diderot. 
3 La troisième partie est consacrée au Rêve de D'Alembert: l'hypothèse de la sensibilité de la matière et le «matérialisme vitaliste» de Diderot (p. 160) sont au centre de l'analyse. Ghorbel souligne l'originalité de la réflexion des dialogues du Rêve, ainsi que l'expressivité littéraire du texte. On trouve de nombreuses analogies et comparaisons avec les articles de l'Encyclopédie dans cette partie. Dans la conclusion, Ghorbel réitère son choix d'un corpus formant un triptyque et confirme un acheminement de la pensée de Diderot vers Le Rêve de D'Alembert, qu'il considère comme un aboutissement philosophique.

4 Renforcer le statut de Diderot comme un penseur authentique et original est de première importance pour la recherche dix-huitièmiste. L'objectif choisi mérite ainsi l'estime des diderotistes. Je voudrais toutefois attirer l'attention sur de fréquentes répétitions du livre: non seulement des répétitions lexicales (Le Rêve de D'Alembert étant «l'œuvre maîtresse» (p. 21), le «sommet» (p. 23), «l'ouvrage maître» (p. 119), la pensée diderotienne étant «décousue», «déroutante», «déconcertante»), mais aussi des répétitions (ou réemploi) d'arguments thématiques, tel que la mention du ruban du père Castel comme une métaphore de la gradation dans l'organisation de la matière. Les articles de l'Encyclopédie sont cités sur Wikisource alors qu'on dispose des éditions plus fiables (éditions originales du XVIII ${ }^{\mathrm{e}}$ siècle, ENCCRE ou les volumes v-viii des CEuvres complètes de Diderot). De plus, présenter les «métaphysiciens» comme les adversaires de Diderot est discutable: "métaphysicien» se définit mal comme une catégorie homogène, opposée au matérialisme, puisque cela supposerait une équivalence entre le théisme et la métaphysique, ce qui n'est pas toujours le cas.

5 Soulignons toutefois l'engagement de l'auteur pour restituer à la «philosophie expérimentale» de Diderot sa place dans l'histoire de la pensée. L'usage qu'il fait des écrits des diderotistes, se référant non seulement aux grandes études classiques mais aussi aux travaux des chercheurs plus jeunes, est également notable. 